\title{
University examination: The examiners perspective
}

\author{
Suresh Chari ${ }^{1}$, Amruta V. Dashputra ${ }^{2, *}$, Madhur Gupta ${ }^{3}$ \\ ${ }^{1}$ Professor, ${ }^{2}$ Assistant Professor, ${ }^{3}$ Professor \& HOD, ${ }^{1,3}$ Dept. of Biochemistry, ${ }^{2}$ Dept. of Pharmacology, NKP Salve \\ Institute of Medical Sciences, Nagpur, Maharashtra, India
}

*Corresponding Author:

Email: avdashputra@gmail.com

\begin{abstract}
Introduction: Education is a joint process, of teachers managing and arranging curriculum resources and of students acquiring the necessary understanding, sensibilities and skills. Evaluation is an integral part of this system. Examiners approach may affect student's performance during summative exam. For the benefit of students it is important to know the examiners views towards students.

Objective: To analyze examiners views while evaluating student's performance during theory and practical examination.

Material and Methods: After ethics approval a validated questionnaire based cross-sectional study was conducted at NKPSIMS \& RC. Questionnaire was categorized into- (A) General questions, (B) Questions related to theory paper correction, (C) Questions regarding practical examination and viva. Questionnaire was given to teachers $(\mathrm{n}=62)$ who were examiner for university examination in their respective subject.

Statistical Analysis: Mean, Standard Deviation (SD) and percentage was derived for each item.

Results: Teachers gave much importance to theory paper correction (Mean 7.40, SD 2.33) and practical examination \& viva (Mean 8.61, SD1.51). They gave maximum importance to content of answer sheet (Mean 8.47 SD 1.89) and least importance to number of pages filled by student (Mean 5.13 SD 2.87). Most of teachers gave importance to knowledge of student (Mean 9.35, SD 1.08). Conclusion- In present study teachers had given much importance to content of answer sheet in theory paper correction and knowledge \& competency during practical examination.
\end{abstract}

Keywords: Summative examination, University examiner, Written examination, Practical examination.

\section{Introduction}

Medical education is a joint process, of teachers managing and arranging curriculum resources and of students acquiring the necessary understanding, sensibilities and skills. This has made education a systematic pursuit. Evaluation is an integral part of this system. In the field of education, evaluation is understood as examination by someone else- teacher or any board, university etc, of students who have been educated in a certain way for a particular subject or course. ${ }^{1}$ For evaluation to be complete, the measurement must be followed by a value judgment as to the extent to which the objectives have been achieved. The measurement can be qualitative or quantitative and value judgment should concern with the desirability of the result of the measurement. ${ }^{2}$

Evaluation has several applications in the field of education. The most important application of evaluation are for continued monitoring of learning activities for giving a feedback (formative evaluation) or for certifying competence to complete a course (summative evaluation). The primary purpose of formative evaluation is to determine how much and how well students have learned, to serve as a feedback to students and teachers. It is of great help in detection of learning difficulties which can be corrected by counseling to modify learning methods or activities. Decisions about whether to use formative or summative assessment format, how frequently assessments should be made, and what standards should be in place remain challenging. (1) Medical Educator also face the challenge of developing tools for the assessment of qualities such as professionalism, team work and expertise that have been difficult to define and quantify. ${ }^{3}$

The purpose of summative evaluation is to know whether the student is competent enough for certification. $^{2}$ Summative examination in medical college is conducted at university level. In university examination, for impartial assessment it has been recommended that besides internal examiner, external examiner should assess student during practical examination. Internal and external examiners approach may affect student's performance during summative exam. For the benefit of students, understanding the examiners views towards students are very crucial. Hence this project has been designed to find out examiner perspective while evaluating student during theory and practical examination The study specifically intends to find out- 1) How an external examiner views the process of university examination. 2) Does the examiner have any preconceived notions about the examination process. 3) What are the priorities of an examiner, when he conducts an examination.

\section{Objective}

To analyze examiners views while evaluating student's performance during theory and practical summative examination. 


\section{Material and Methods}

After ethics approval a questionnaire based crosssectional study was conducted at NKP Salve Institute of Medical Sciences and Research Centre (NKPSIMS \& RC). Questionnaire was categorized in questions regarding theory and practical evaluation for summative examination. It comprised of (A) General questions -8 items, (B) Questions related to theory paper correction 12 items, (C) Questions regarding practical examination and viva-14 items .In this questionnaire, questions rated on $1-10$ scale $(1=$ not important, $10=$ most important) and few questions were with multiple choice options and one open ended question.

In this study questionnaire was validated by 10 members of Medical Education Technology of Unit of Institute. This prevalidated questionnaire was given to teachers of preclinical and clinical departments of NKPSIMS who were examiner for university examination in their respective subject. Before giving the questionnaire, informed consent was taken from teachers after explaining purpose of study. Total 62 teachers participated in this study. Questionnaire was collected from respective departments within 8 days of distribution of questionnaire.

\section{Statistical Analysis}

Statistical analysis was done by using Epi -info software, version 6. Mean, Standard Deviation (SD) and percentage was derived for each item.

\section{Results and Discussion}

Assessment can reinforce student's intrinsic motivation to learn and inspire them to set higher standards for themselves. ${ }^{4}$ Formative assessment is guiding future learning, providing reassurance, promoting reflection and shaping values. Although summative assessment is intended to provide professional self regulation and accountability, it may also act as a barrier to further practice or training. Summative assessment may not provide sufficient feedback to drive learning. But students tend to study only what they expect to be tested on, so summative assessment may influence learning even in the absence of feedback. ${ }^{5}$

Medical knowledge and clinical skills of medical students are often assessed using written and oral examinations. The written examinations are usually composed of long and short answer question of one type or another, which were graded by hand. The oral examination (viva voce) typically required the student to go to a patient's bedside, gather information and then present a diagnosis and treatment plan to assessor who asked questions and made judgment about the performance of student. ${ }^{6}$ Domain wise matrix of evaluation shows that written examinations mainly focus on cognitive domain, whereas as by practical examination we can test psychomotor and affective domain. ${ }^{1}$
General questions: In the present study most of the participant teachers were examiners in the university since 5-10 years. Participants gave much importance to theory paper correction in university exam (Mean 7.40, SD 2.33). Even more importance was given by them on practical examination \& viva (Mean 8.61, SD1.51). Most of them opined that visiting new place is not important for them (Mean 5.69, SD 2.87). Very little importance was given by teachers on issue of socializing with colleagues during practical examination. (Mean 5.89, SD 2.43). Most of examiners do not give importance to remuneration and hospitality offered by institute (Mean 5.50, SD 3.23, Mean 6.68, SD 2.48 respectively).

In Theory paper correction: In this area participant had given maximum importance to content of answer sheet (Mean 8.47, SD 1.89) and least importance to number of pages filled by student (Mean 5.13, SD 2.87). Student who tries to beat around the bush does not influence the teacher. It did not affect the marks given by teacher. $(38 / 62,61.3 \%)$

Practical Examination \&Viva: In this study regarding viva of practical exam, examiners gave maximum importance to knowledge of student (Mean 9.35, SD 1.08). This question had the highest score in this study. This score was followed by confidence of student (mean 7.69, SD 1.65), language and fluency (mean 7.05, SD 1.71), and appearance of the student during practical examination (mean 6.21, SD 2.40). Result of this study showed that, while conducting practical exam, most of teacher had friendly attitude towards students $(88.70 \%)$. They try to assess knowledge as well as competency of student (85.5\%). It is critical for a doctor to be able to communicate effectively with patients but an assessment of this aspect of competence is not tested well during examination. ${ }^{7}$

If the goal of a particular educational intervention is increased knowledge then a written assessment will motivate students to study from books. Similarly, a goal of increased clinical skill is best supported by a clinical assessment that motivates students to interact with patients. Thus the educational effect of assessment capitalizes on student's motivation to do well and direct their study efforts in support of the curriculum. ${ }^{8}$ There have been rapid and extensive changes in the way assessment is conducted in medical education. Several new methods of assessment have been developed and implemented over the time and they have focused on clinical skills, communication skills, procedural skills and professionalism. ${ }^{9}$ Programmatic assessment is an integral approach to the design of an assessment program with the intent to optimize its learning function, its decision-making function and its curriculum quality-assurance function. ${ }^{10}$

Practical examination has its drawbacks like; in general practical examination is very extensive. Qualified examiners are needed and that to be not repeated every year, so there is need to build a large 
pool of examiners for university examination. Increased use of resources, a decrease in exam quality and higher degree of subjectivity during examination are points of concern. The use of multiple method of assessment can overcome many of the limitation of individual assessment formats. It will decrease subjectivity in assessment. $^{5}$

As there is no counter check on the examiners about their ability, knowledge and integrity, giving them the power to decide the capability of examinees which makes examiners more rigid and close minded. ${ }^{1}$ However results of present study showed that most of examiner $(55 / 62,88.7 \%)$ were of the opinion that if there is difference of opinion during answering a question, candidate should be free to justify his/ her answer to examiner. Teachers opined that role of internal examiner in passing the student is very important $(83.9 \%)$ because internal examiner has an actual idea about a student's caliber from the interaction over the course year. Regarding students appearing for second attempt teacher were of the opinion that such students should be examined as equal to the regular candidate $(67.70 \%)$.

Student study more thoughtfully when they anticipate certain examination format. The unintended effect of assessment includes the tendency for students to cram for examination and to substitute superficial knowledge for reflective learning. ${ }^{5}$ In present study most the teachers $(91.9 \%)$ opined that a candidate with poor performance may be passed if he/she has shown sincerity and hard work during the assessment year. According to them poor performance during summative examination may be because of some reasons like poor health, stress, death or illness of near one etc. In their opinion sincerity and hard work are the important factor for becoming a good clinician. The medical profession has always received good respect from the society. With the change in health needs of societies, increase in the expectation of society, increase in numbers of medical students, proliferation of new disciplines and pressure on curricular time, there is general feeling that the competence of doctors, at the end of MBBS ( Bachelor of Medicine Bachelor of Surgery) course does not match the expectations. It is recognized that the teaching of attitudes and skills is an essential component of ability profile of clinician and should received adequate emphasis in learning and assessment. (11) If during evaluation not only knowledge but competency as well as communication skill be assessed by examiner, then it will be one step towards producing good Indian medical graduate (IMG).

This study is one of its kind since we were not able to get any references which were closely or remotely concerned with this study. We are not surprised with the results and it is encouraging to know that most of the teachers who come as examiner have academics in mind and do not give much importance to other things like hospitality, socializing with colleagues, accommodation and remuneration.

The positivity of examiners towards achieving objectives of examination as said by university is no doubt, very encouraging. Indirect impact of this study might be that teachers become more vigilant about aspects which have to be assessed during examination. We strongly feel that results of study should be shared with undergraduate students. So that unnecessary, unwarranted confusion, apprehension and fear about examiner in the mind of students could be reduced.

During informal focused group discussion with teachers we came to learnt that the teachers who were examiner can influence the mindset of student by either creating an environment of fear or could ease the tension which is a normal phenomena for student to experience before the examination. The result of this study could be used as evidence to counsel these teachers about the importance of creating a non threatening environment about both examiner and examination, which could be a huge contribution in the success of student who is looking to be competent Indian Medical Graduate.

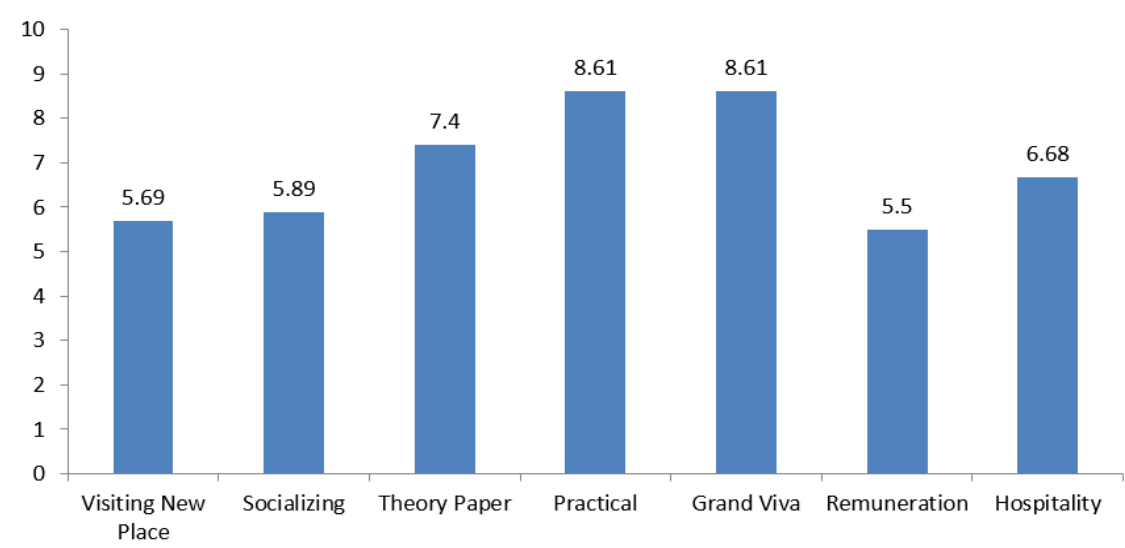

Fig. 1: Teachers views on General questions $(n=62)$ 


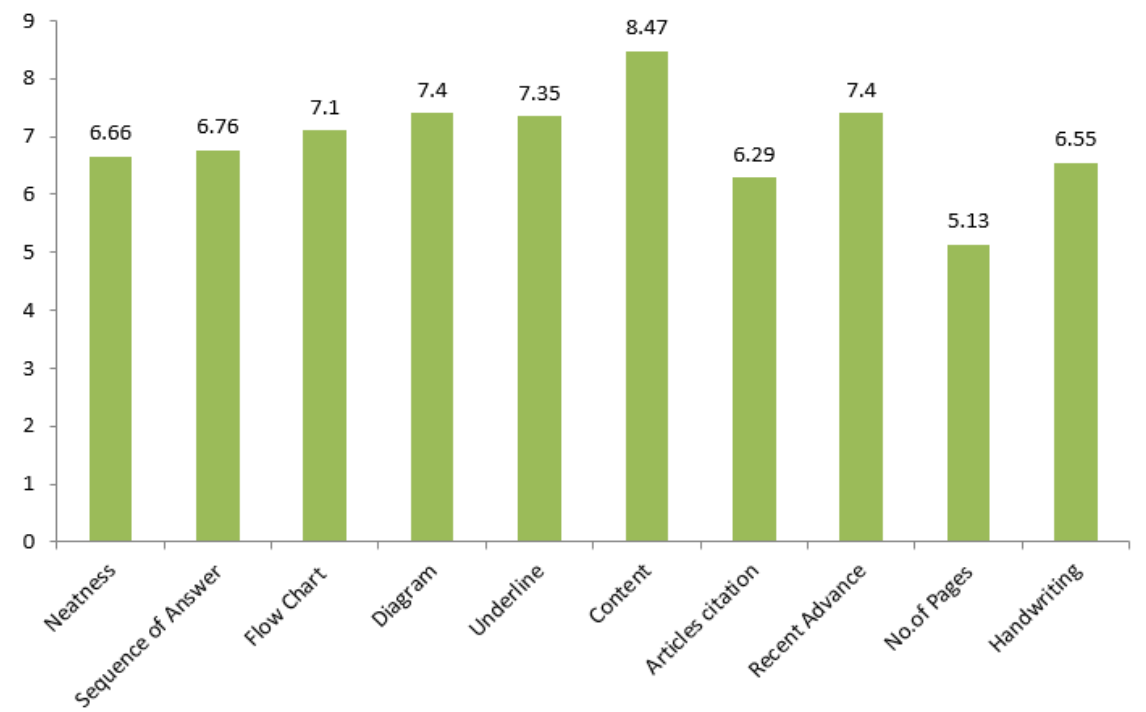

Fig. 2: Teachers view on Theory paper correction $(n=62)$

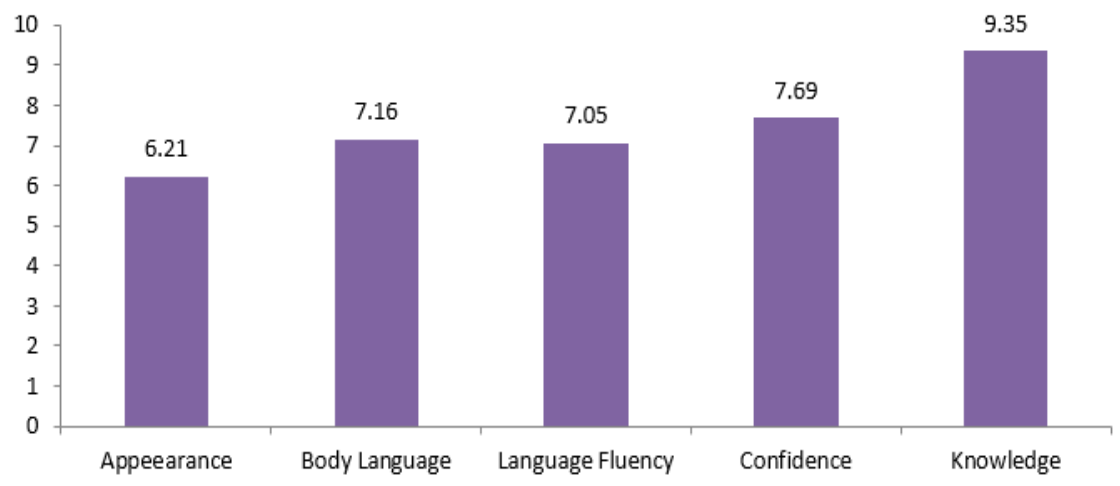

Fig. 3: Teacher views on Practical Examination and Viva (n=62)

\section{Conclusion}

In present study teachers have given much importance to content of answer sheet in theory paper correction and knowledge \& competency during practical examination.

\section{References}

1. Mehta L A. Evaluation. Editors, S Bhuiyan, N Rege, A N Supe. The Art of Teaching Medical Students, Mumbai Medical Education Technology cell, Seth GSMC and KEM hospital. 2nd Edition 2002. p195-210

2. N Ananthkrishnan. Evaluation. Editors, $\mathrm{N}$ Ananthkrishnan, K R Sethuraman, Santosh Kumar Medical Education .Principles and Practice. 2nd Edition Pondicherry: Alumni Association of National Teachers Training Centre, JIPMER, Pondicherry. 2000. p 99-106.

3. Cox M, Irby D M. Assessment in medical education. New England Journal of Medicine. Jan 2007;24:387-96

4. Ben F, David M. The role of assessment in expanding professional. Horizons Medical Teacher 2000;22:472-77.

5. Epstein R M. Assessment in Medical Education. Medical Education .Editors Malcolm Cox r, David M Irby. N Eng J Med 2007;356:387-96.

6. Norcini JJ, McKinley D W. Assessment methods in medical education. Teaching and Teacher education 2007; 23:239-50.
7. Boulet J. R., Rebbecchi T R, Denton EC, McKinley D W, Whelan G P . Assessing the written communication skills of medical school graduates. Adv Health Sci Educ 2004;9:47-60

8. Van der Vleuten C P M, Schuwirth L W. Assessing professional competence: From method to programmes. Med Educ 2005;39(3):309-17

9. Issenberg S B, McGaghie W C, Hart I R, Mayer J W, Flener J M, Petrusa E R et al. Simulation technology of health care professional skills training and assessment. $J$ Am Med Assoc 1999;282:861-66.

10. Van der Vleuten C P M, Schuwirth L W, Driessni E W, Govaertsi M J B , Heenemani S. Twelve Tips for programmatic assessment. Med Teacher 2015;37:641-46.

11. Mehta M, Adkoli B V, Nayar U. Attitudes and skills of Doctors. Editors, S Bhuiyan, N Rege, A N Supe. The Art of Teaching Medical Students, Mumbai Medical Education Technology cell, Seth GSMC and KEM hospital. 2nd Edition 2002. 2002. p145-154. 